\title{
3D SURVEYING AND FORMAL ANALYSIS OF A STRUCTURAL BAY OF A GOTHIC APSE
}

\author{
D. Moreno-Garcia ${ }^{1 *}$, S. Coll-Pla ${ }^{1}$, A. Costa-Jover ${ }^{1}$, A. Samper-Sosa ${ }^{1}$ \\ ${ }^{1}$ Department of Architecture, Universitat Rovira i Virgili, Av. Universitat 1, Campus Bellisens, 43204 Reus, Spain \\ *david.moreno@urv.cat
}

Commission II

KEY WORDS: terrestrial laser scanner, formal analysis, methodology, gothic apse, vaults, geometry, Cathedral of Girona

\begin{abstract}
:
In recent years, the development of massive data capture techniques such as Terrestrial Laser Scanner (TLS) have made it possible to develop new procedures to evaluate architectural heritage with a high level of accuracy. The study proposes a workflow to identify formal anomalies in the main elements that form a structural bay of the apse of the Cathedral of Girona, studying arches, vaults, buttresses and pillars. The methodology is based on different two-dimensional and three-dimensional procedures, and the database obtained that could help in future research to relate the results with the different construction phases and being applicable to other constructions of similar typology.
\end{abstract}

\section{INTRODUCTION}

The research arises from the possibilities offered by point clouds obtained through massive data capture techniques, such as the Terrestrial Laser Scanner (TLS), for the study of heritage buildings. Therefore, the objective of this communication is to establish a workflow to identify formal anomalies in the main structural elements The research is carried out using existing software to systematize an easy and agile methodology. This information can have an impact on heritage conservation strategies, and also on historical studies.

The methodology is applied in a structural bay of a Gothic apse, in this case, the apse of the Cathedral of Girona. The most relevant structural elements are studied: arches, vaults, buttresses and pillars.

The Cathedral of Santa María de Girona is a large building with a high formal complexity. In this context, the use of a TLS, allowed to obtain a topographic survey of the complex in 2019 (Coll-Pla, Costa-Jover, Moreno-García, Samper-Sosa, 2019), with unprecedented detail and precision (Figure 1).

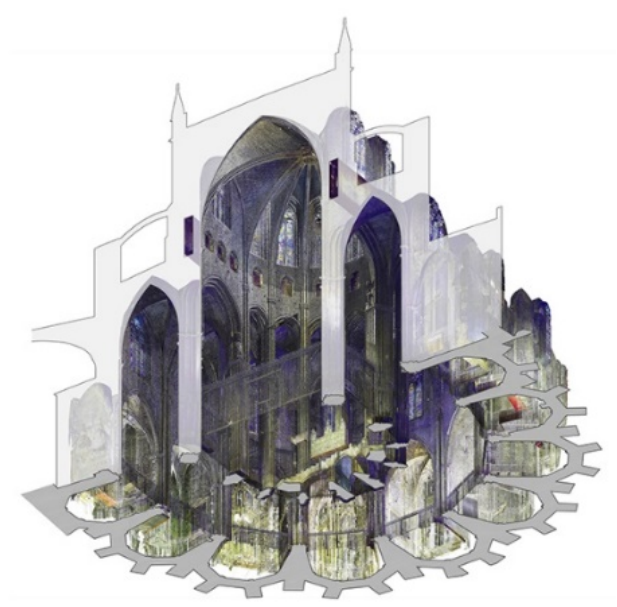

Figure 1: Apse of the Girona Cathedral. Image of the survey in a terrestrial laser scanner and type section.

\section{RELATED WORKS}

Current procedures, such as digital photogrammetry and TLS, have become widespread in recent years for surveying and evaluating built heritage. They are especially useful for historical constructions, since the architecture is complex and irregular, and in addition, many elements, such as vaults and domes, are not accessible. The use of laser scanning allows the rapid and accurate generation of the point cloud that defines in a threedimensional way the shape of an object or the formal elements of a building (Boardman, et al., 2018). Many investigations have demonstrated the reliability of these procedures (Kadobayashi et al. 2004), (Grussenmeyer et al. 2008), testing their effectiveness and compatibility to examine the geometry of a building with high precision. This makes it possible to detect and monitor degradation processes and formal anomalies, but also to improve historical knowledge about the analyzed element.

Managing and working with point clouds to obtain useful information today requires time-consuming processes with a lot of "manual" work. The detection of formal anomalies is a key issue, as possible deformations have a direct impact on the conservation of heritage buildings. Many works approach this issue from different approaches, such as the study of the Temple of Diana in Baiae (Sinopoly et al. 2021) or the Church of Cantalovo (Bonali et al. 2014), among many others. In addition, some recent research is related to the use of HBIM (Barontini et al. 2021), while others delve into the automation of processes to perform structural assessments (Angjeliu et al. 2019).

The research presented has as direct precedents the works carried out in the Cathedral of Tortosa (Costa et al. 2017). and the church of Sant Miquel de Batea (Costa et al. 2021), where an initial systematization for the analysis of formal anomalies through simple procedures was tested. Current research goes a step further in that purpose, especially in the case of vaults. 


\section{DEVELOPED METHODOLOGY}

The survey with a TLS was carried out in a single campaign, that included the scanning of all the exterior and interior areas belonging to the Cathedral complex. The Leica RTC 360 scanner was used, with an accuracy of $5.3 \mathrm{~mm}$ at a distance of $50 \mathrm{~m}$; angular accuracy 18" / 18"; without the use of lenses and with an average alignment error between positions of $2 \mathrm{~mm}$. The recording and verification between positions were done using the Cyclone Register 360 software, where once the result was validated, it was exported to the Cyclone program in the same local coordinate system.

The study focuses on the apse generator module, and further research will deal with the rest of the header to establish a comparative study. The module chosen is the one located in the central position of the apse, which corresponds to the first chapel built, according to the historical archive (Sureda, 2005). In general terms, the methodology is based on $2 \mathrm{D}$ and $3 \mathrm{D}$ processes, which are selected based on the characteristics of the construction element, and the parameters to be evaluated. A nomenclature is also established to distinguish the different elements of study (Figure 2).

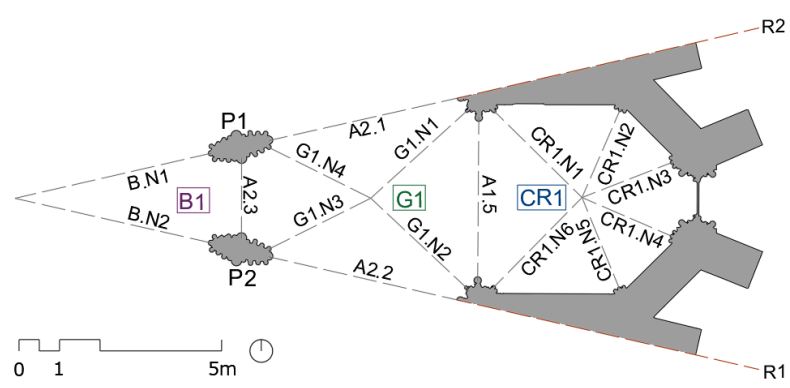

Figure 2: Nomenclature of the elements.

\subsection{Arches}

In the two-dimensional study of the toral arches of the vaults, selected data are obtained such as impost heights (a, a'), maximum height ( $b$ or $b^{\prime}$ for deductions of arch layout on the vault key), beginning of arch (u, u'), span (l) and ratio between span and height (h) (Figure 2). All heights are taken with respect to a common horizontal reference plane (r), previously fixed to avoid erroneous measurements, since the level of the pavement can vary.
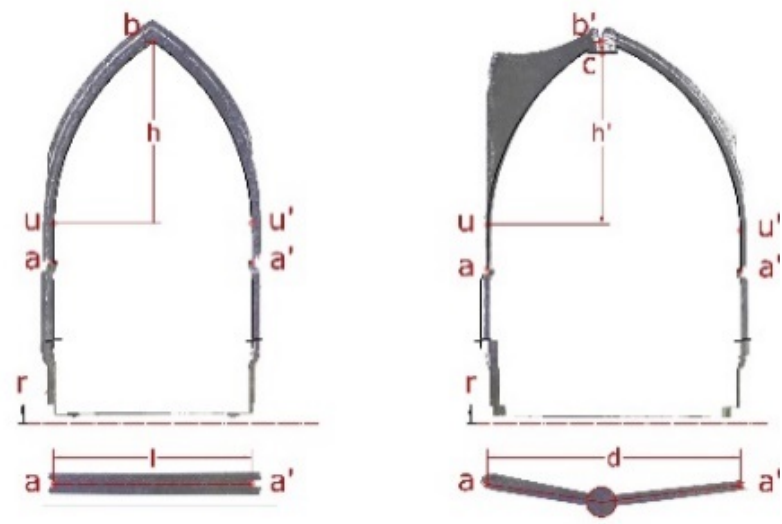

Figure 2: Two-dimensional parameters to be obtained from the arches (left) and ribs (right).
From the global point cloud, the edge of each of the arches and ribs that make up the traces of the geometry of the bay. Once the TXT coordinate files of each of the edges are obtained, a customized program has been developed to calculate the geometric regression circumference of each cloud $\mathcal{N}_{i}$, where $i$ equals to the edges of the arches: A1.11, A1.1r, A2.11, A2.1r, A2.21, A2.2r, A2.31, A2.3r, G1. N1, G1. N2, G1. N3, G1. N4, B.N1, B.N2. The equation is sought, which is the one $\theta \equiv$ $B x^{2}+B y^{2}+E x+F y+1=0$ that best fits the cloud minimizing the next sum of quadratic residuals $\sum_{i=1}^{i=n} \varepsilon_{i}^{2}=$ $\sum_{i=1}^{i=n}\left(B x_{i}^{2}+B y_{i}^{2}+E x_{i}+F y_{i}+1\right)^{2}$. The solution of the problem of the calculation of $\theta$ is offered by Gauss's normal equations by solving:

$$
\left(\begin{array}{ccc}
1_{i}\left(x_{i}^{2}+y_{i}^{2}\right)^{2} & x_{i}\left(x_{i}^{2}+y_{i}^{2}\right) & y_{i}\left(x_{i}^{2}+y_{i}^{2}\right) \\
x_{i}\left(x_{i}^{2}+y_{i}^{2}\right) & 1_{i} x_{i}^{2} & x_{i} y_{i} \\
y_{i}\left(x_{i}^{2}+y_{i}^{2}\right) & x_{i} y_{i} & 1_{i} y_{i}^{2}
\end{array}\right)\left(\begin{array}{l}
B \\
E \\
F
\end{array}\right)=\left(\begin{array}{c}
-1_{i}\left(x_{i}^{2}+y_{i}^{2}\right) \\
-1_{i} x_{i} \\
-1_{i} y_{i}
\end{array}\right)
$$

Once the regression circumferences have been calculated, they are drawn with their corresponding section of points with AutoCAD.

\subsection{Vaults}

For the vaults,

by means of two-dimensional sections the same data of the ribs are obtained as in the study of the arches (a, a ', u, u'), with the difference of the theoretical maximum height of the arch ( $\left.b^{\prime}\right)$ and the vault key (c), the diagonal span (d) and the relationship between diagonal and height $\left(h^{\prime}\right)$ (Figure 2). The same calculation of the regression circumference is also performed as in the arches.

The three-dimensional study is developed by means of the software Cyclone 3DR. A comparative study of the point cloud is carried out with respect to primitive forms. First, the overall vault is compared with a horizontal reference plane located in the lowest impost (Figure3). Following, the webs are compared with cylinders that best fits their shapes. For the study of webs, the vault of the chapel is eliminated from the research because it is incomplete due to the occupation of space by the altarpiece.

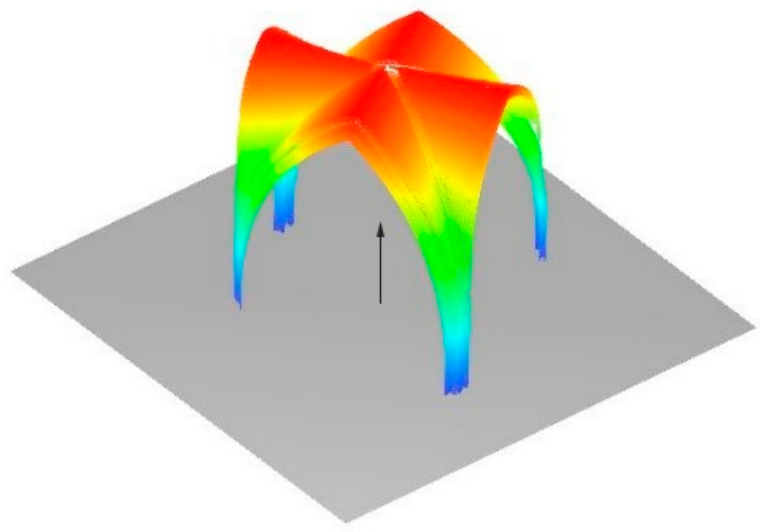

Figure 3: Comparison of the vault G1 with horizontal plane.

$3 \%$ of the worst points of each cloud (outliers) are eliminated for each web (Figure 4). In the case of vault B1 the curvature of the arches and webs begins above the imposts. Thus, the straight areas above the imposts are eliminated from the comparison. 


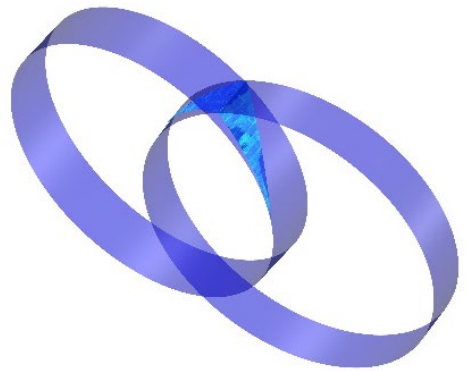

Figure 4: Search for the best cylinder for the webs.

In addition, performing a meshing process with Cyclone 3DR allows to generate a mesh, with an average triangle size of $2.5 \mathrm{~cm}$ subsequently refined, on which a topography of the vaults can be generated, through horizontal sections every $10 \mathrm{~cm}$ with respect to the lowest impost height, generating verifiable and complementary information with the flatness study.

\subsection{Pillars}

In the pillars, the two-dimensional study is used to identify the value of the out of plumb in height, by means of two horizontal sections (the first at the bottom of the pillar, and the second just under the capital), obtaining the value and direction of the pillar's leaning (Figure5). To do this, the point cloud of each pillar is isolated and only the shaft is used for the study, separating it from the base and the upper capitals.
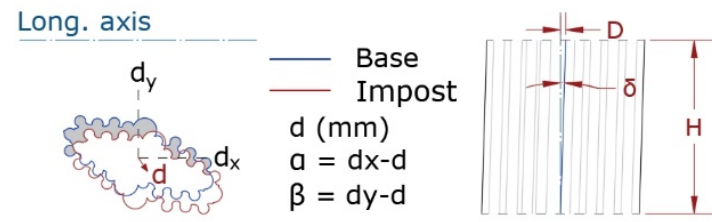

Figure 5: Two-dimensional parameters of the horizontal displacement.

Three-dimensionally, a comparison is made between the theoretical section of the column with respect to the real point cloud, obtaining a flatness graph where it can be identified if a buckling or twisting movement occurs in the pillar. To do this, the section of the base of the pillar is taken as a reference, it is modeled geometrically and it is extruded along the axis of the shaft. Due to the formal complexity of the pillar, it is not possible to proceed with an elevation display. Therefore, the two longitudinal elevations of the pillar are extracted where the anomalies can be identified and located in space.

\subsection{Buttresses}

Two-dimensional analysis on the two buttresses is used to obtain the value of their leaning. A cross section of points is made for each buttress that allows to obtain a polyline, with a chaining distance between points of $0.0103 \mathrm{~m}$, on which a verticality check is carried out through AutoCAD, thus obtaining the value of its out of plumb.

Three-dimensionally, a flatness analysis of their main faces is carried out in order to detect possible bulges in the buttress or physical pathologies derived from their ashlars. By searching for the plane that best suits the surface of the buttress face (Figure 6), you can compare the distance to this of the points, obtaining a gradient of distances. To refine the results, a cleaning of the outlier points of each face is carried out, corresponding to $3 \%$ of the total points.

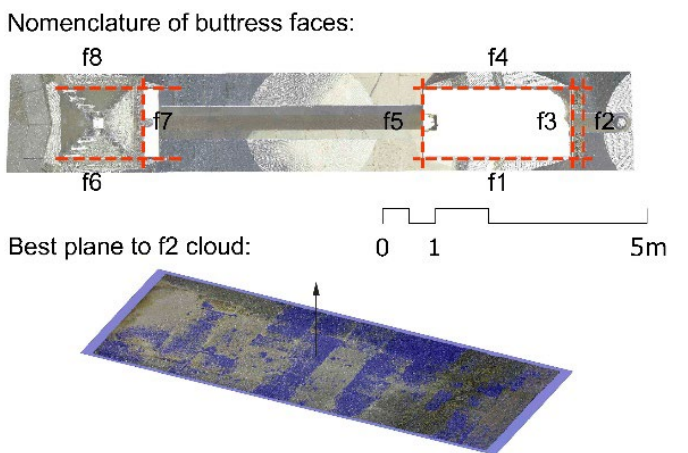

Figure 6: Study of flatness by means of the best plane and buttress nomenclature.

\section{RESULTS}

The proposed methodology has made it possible to obtain both qualitative and quantitative data on the formal differences of the arches, ribs, vaults, pillars and buttresses that constitute the longitudinal radial module of the apse of the Cathedral of Girona.

\subsection{Arches}

In the following table (Table 1) it can be seen the measurements obtained through sections referring to heights of arches and ribs. It has not been possible to obtain some heights of the vault of the CR1 chapel due to the occupation of the space by the altarpiece. With the data obtained, the average of each point measured in relation to its similar arches $\left(a, c, b^{\prime}, u, 1 / 2\right)$ or between extreme values $\left(a-a^{\prime}, u-u^{\prime}\right)$ is also made.

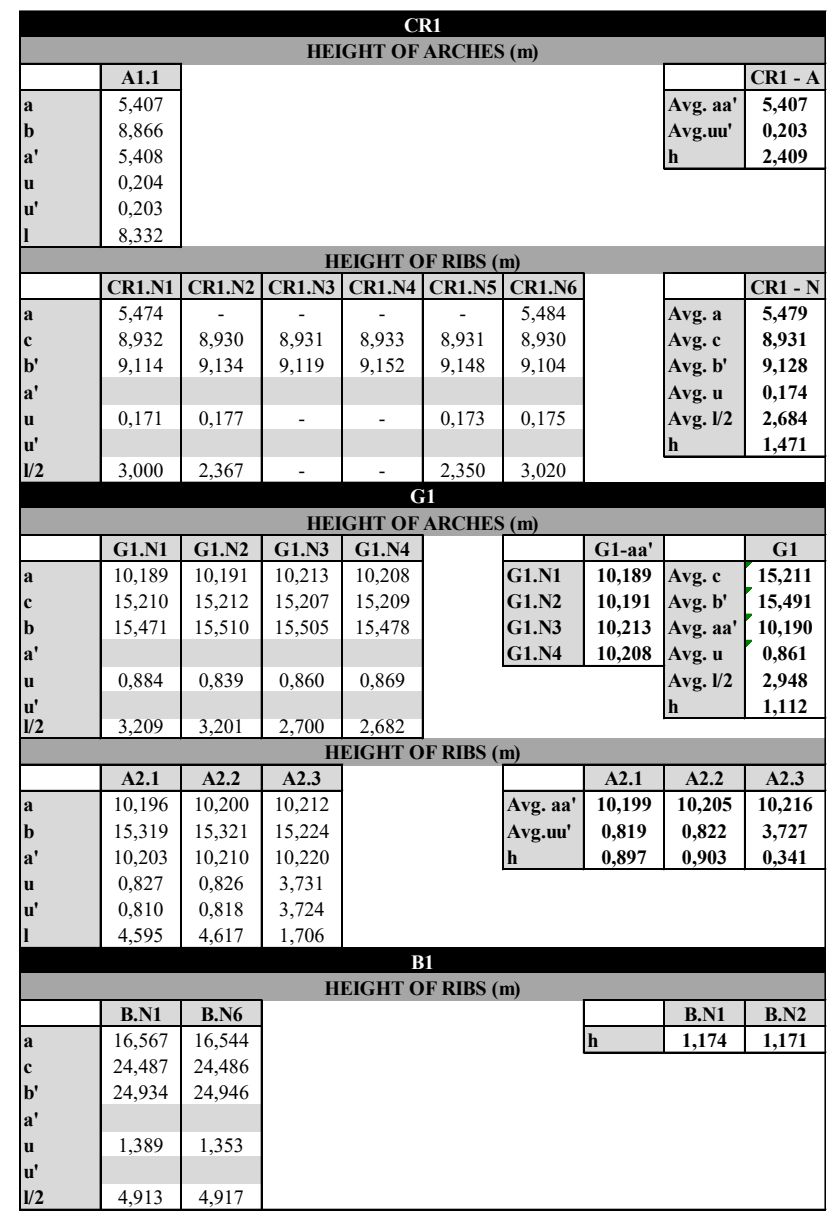

Table 1: Values of heights obtained from arches and ribs. 
The results show some differences between similar ribs but without a significant difference, being less than $5 \mathrm{~cm}$. The relationship between the height and the span of the arches (h) allows to see how the arch with the least pointed path is the A1.1 with a value of $2,409 \mathrm{~m}$, while the most pointed arch is the one used in the A2.3, with a value of $0.341 \mathrm{~m}$. These results show that the trace of each type of arch is unique and there is no common pattern. It should be remembered that the measurements of b', are obtained by elongation of the curvature of the real rib to the vertical of the vault key, therefore, only the result of the average is important and not the individual of each rib.

Applying the procedure of calculation of the regression circumference for each of the edges of arches and ribs, the results are tabulated in Table 2 and graphed in Figure 7.

\begin{tabular}{|l|c|c|c|}
\hline Arch & Points & $\begin{array}{c}\text { Regression } \\
\text { Radius }\end{array}$ & $\begin{array}{c}\text { Adjusted } \\
\text { coefficient of } \\
\text { determination } \\
\text { (\%) }\end{array}$ \\
\hline A1.11 & 11529 & 3.653 & 93.929 \\
A1.1r & 10143 & 3.657 & 95.634 \\
A2.11 & 10956 & 5.247 & 99.992 \\
A2.1r & 7696 & 5.144 & 99.110 \\
A2.21 & 9832 & 5.015 & 90.272 \\
A2.2r & 8777 & 5.253 & 99.960 \\
A2.31 & 6627 & 1.197 & 99.679 \\
A2.3r & 7353 & 1.296 & 99.344 \\
G1.N1 & 36398 & 4.728 & 98.972 \\
G1.N2 & 28768 & 5.002 & 99.905 \\
G1.N3 & 22984 & 5.110 & 96.023 \\
G1.N4 & 21742 & 5.088 & 92.520 \\
B.N1 & 46375 & 7.781 & 99.495 \\
B.N2 & 64922 & 7.921 & 99.986 \\
\hline
\end{tabular}

Table 2: Results of the regression circumferences obtained.

It can be seen in the graphic results that the arches can be grouped into 4 groups. The first is that of the A2.3 arches, with a smaller radius and with a difference between sides of $0.099 \mathrm{~m}$. The second group contains the arches A1.1, with a difference of only $0.004 \mathrm{~m}$. The third group contains the arches A2.21, A2.1r and the ribs of the G1 vault, with the exception of the G1. N1 that moves away with a lower radius $(-0.274 \mathrm{~m})$. The arches A2.11 and A2.2r move away with a greater radius $(+0.109 \mathrm{~m}$ and $+0.103 \mathrm{~m}$ respectively) and cannot be included in the group either. Finally, the fourth group contains the ribs B.N1 and B.N2 that form the central vault of the presbytery, with a difference of radius between $0.139 \mathrm{~m}$.

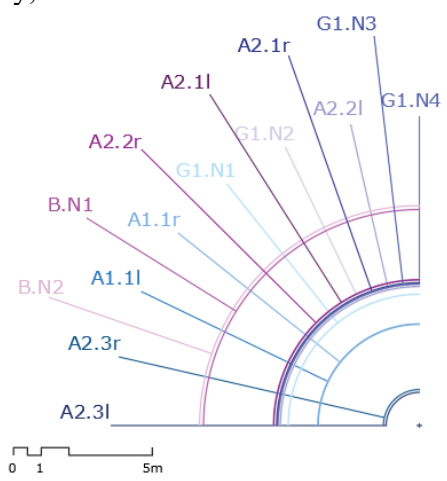

Figure 7: Radius of the different arches and ribs studied.

\subsection{Vaults}

From the three-dimensional study, the results obtained from the comparison of the CR1, G1 and B1 vaults with respect to a horizontal plane at the minimum height of their imposts are first shown. These results are superimposed together with the topographic ones obtained from the vaults (Figure 8).

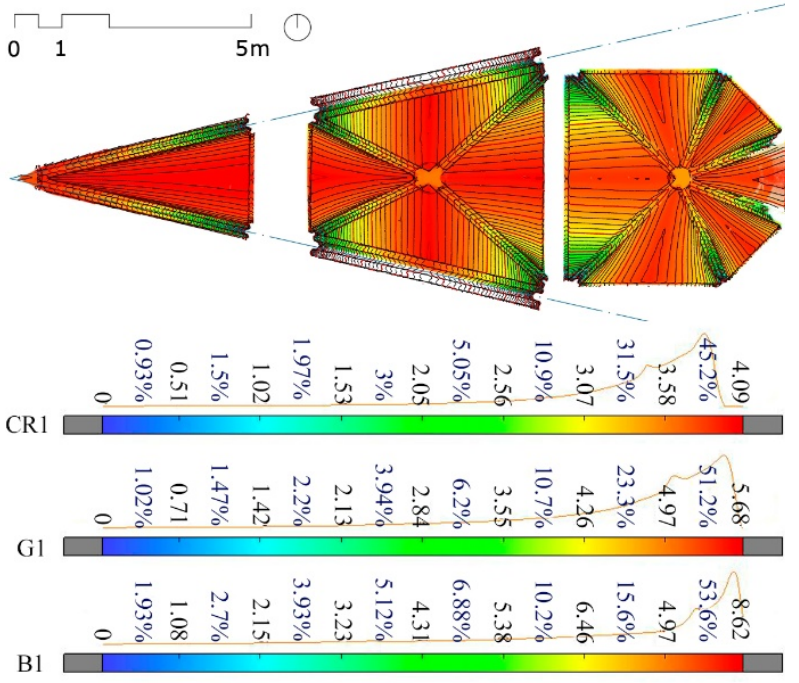

Figure 8: Data obtained by the horizontal plane comparison, superimposed with the topographic data.

The maximum height obtained by the gradient of each vault corresponds to a value of $4,090 \mathrm{~m}$ for the CR1, starting its webs at a height of $0.384 \mathrm{~m}$, from the minimum height of impost located at $5.407 \mathrm{~m}$. For the vault of the G1 ambulatory, the maximum height is $5,680 \mathrm{~m}$, starting the height of webs at $2,228 \mathrm{~m}$ and with a minimum impost height of $10,172 \mathrm{~m}$. For the central vault $\mathrm{B} 1$ the maximum height is $8,620 \mathrm{~m}$, starting the webs at $3,783 \mathrm{~m}$ and $16,536 \mathrm{~m}$ of minimum height of imposts.

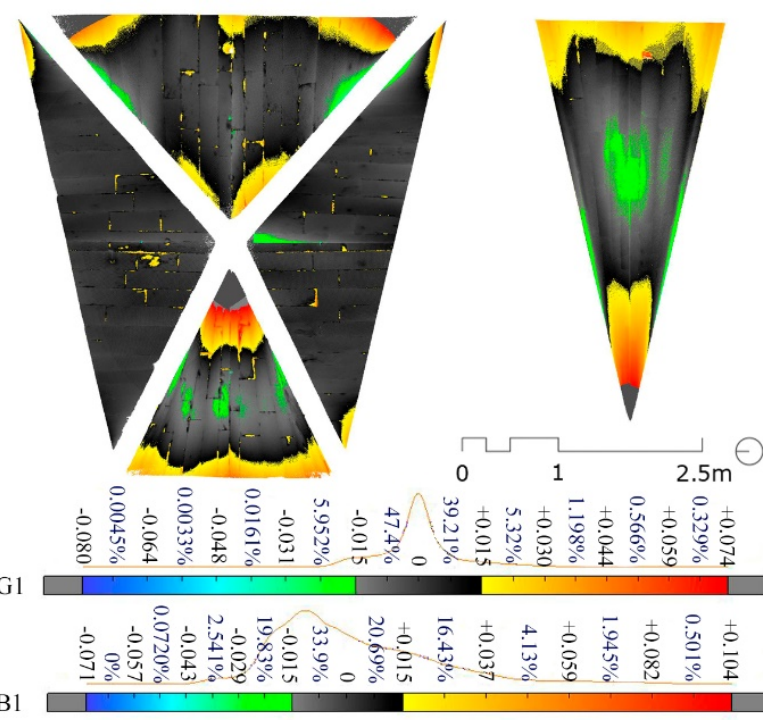

Figure 9: Study of flatness of the webs of vaults G1 and B1.

The graphic results obtained by studying webs with best cylinders (figure 9) show a very high approximation to these. In the case of the G1 vault, most of the differences are in the extreme limits of the webs, with an upper value of $0.074 \mathrm{~m}$ and a lower value of $0.08 \mathrm{~m}$. In the webs p14 and p15 there is a slight bulging towards the interior around $2 \mathrm{~cm}$, and it is also noteworthy that in some joints of the pieces appear higher values between 2 and $3 \mathrm{~cm}$, indicating a possible disintegration of the material between joints. However, the approximation of the webs to the cylinders is $86.81 \%$ of the points. In vault B1, it happens as in the G1, producing a differential pointing to the cylinders at the ends of the vault with a maximum of $0.104 \mathrm{~m}$. The lower values 
correspond only to a bulging inward in the center of the webs and in the central part that delimit with the ribs, with a maximum lower value of $0.071 \mathrm{~m}$. In this case, in the joints between ashlars they do not present values outside the range $\pm 0.015 \mathrm{~m}$ and most of the webs fall into this range with a value of $54.6 \%$.

\subsection{Pillars}

In the study of the pillars P1 and P2, slight deviations have been obtained in the direction of the forces resulting from the weight of the central vault (Figure 10). In the P1 pillar, the horizontal deformation is $16.80 \mathrm{~mm}$ and in section $22.21 \mathrm{~mm}$. The resulting out of plumb is $1 / 377$, which considering the maximum out of plumb regulations between $1 / 300$ and $1 / 500$ would be admissible values. In the case of the P2 pillar, the deformations are minor. In plant the result is $15.10 \mathrm{~mm}$ and in height $15.09 \mathrm{~mm}$. The resulting out of plumb is $1 / 566$, above $1 / 500$ so it is a more than admissible value.

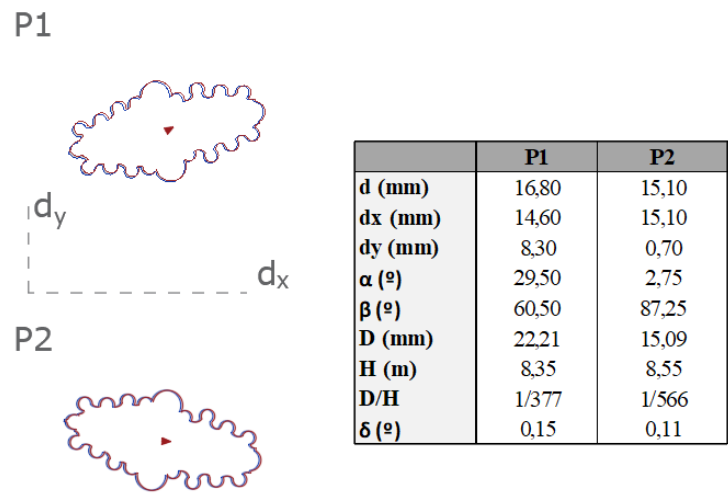

Figure 10: Out of plumbs obtained from the pillars.

Regarding the three-dimensional study and the flatness study, a loss of section ofl $3.8 \%$ of the points between values of 1 and $17.5 \mathrm{~mm}$ at the base of pillar P1 and 3.94\% for pillar P2 is shown. Its high flatness value, $96.16 \%$ for pillar $\mathrm{P} 1$ and $95.99 \%$ for pillar $\mathrm{P} 2$, it could be attributed to a construction error and not to deformation (Figure 11).

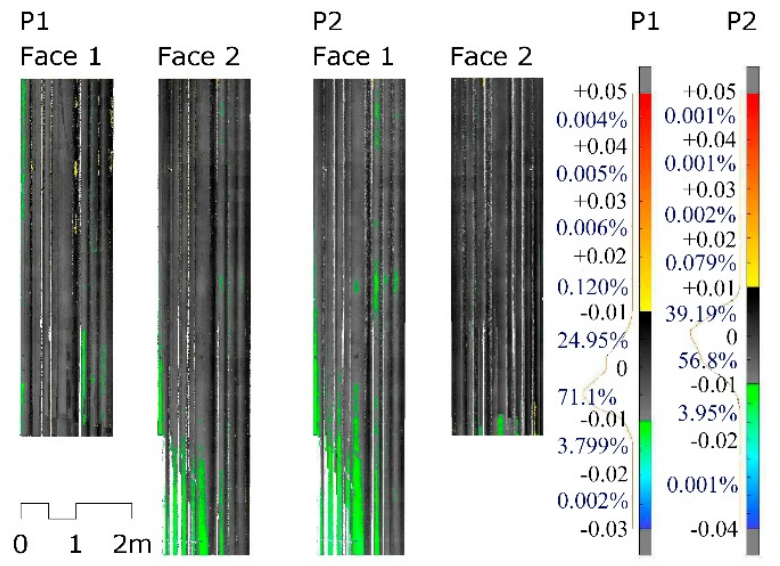

Figure 11: Deployment of the flatness study of the pillars.

\subsection{Buttresses}

As for the buttresses, it is observed that the out of plumb values obtained vary between $2.70 \mathrm{~mm}$ and $4.00 \mathrm{~mm}$ (Table 3 ). These values, taking into account its height between $9,178 \mathrm{~m}$ and $10,122 \mathrm{~m}$, are negligible so that the buttresses of the module are not deformed.

\begin{tabular}{|l|c|c|c|}
\hline & Height (m) & Out of plumb (m) & C/H \\
\hline R1.h1 & 9,197 & 0,040 & $1 / 229$ \\
R1.h2 & 10,107 & 0,027 & $1 / 374$ \\
R2.h1 & 9,178 & 0,033 & $1 / 278$ \\
R2.h2 & 10,122 & 0,038 & $1 / 266$ \\
\hline
\end{tabular}

Table 3: Results of out of plumbs in buttresses.

Three-dimensionally, anomalies in the lower part of buttresses $\mathrm{C} 1$ and $\mathrm{C} 2$ vary between a value of $\pm 0.019 \mathrm{~m}$, while the upper buttresses of the central vault are between $\pm 0.025 \mathrm{~m}$ (Figure 12). The study of flatness in the walls shows that the lower buttresses lack major formal alterations to take into account, except for some slightly protruding ashlars and some negative values that could be caused by the wear of the stone. On the other hand, in the upper part, the front faces show that the last rows of the upper third protrude more than the subtraction of the wall, while in the lateral faces this difference is not reflected (Figure 13).
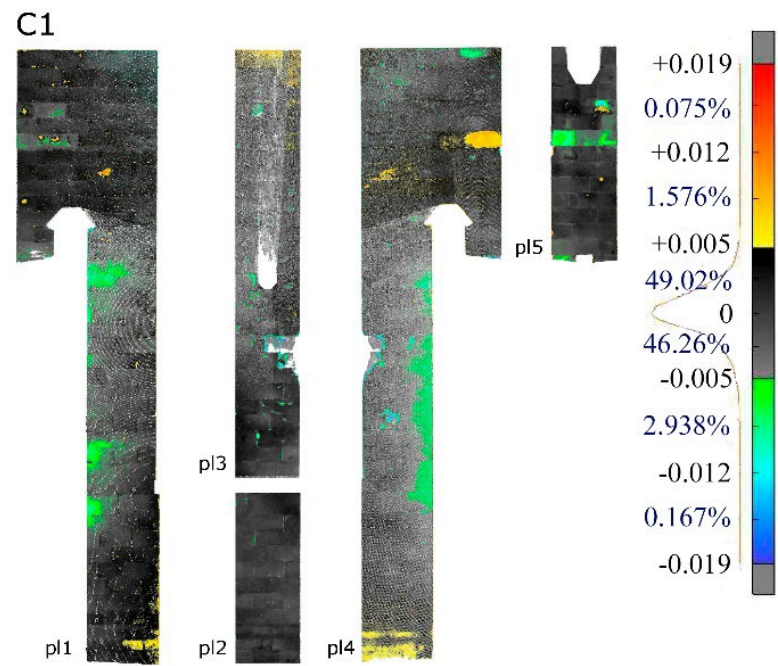

\section{$\mathrm{C} 2$}
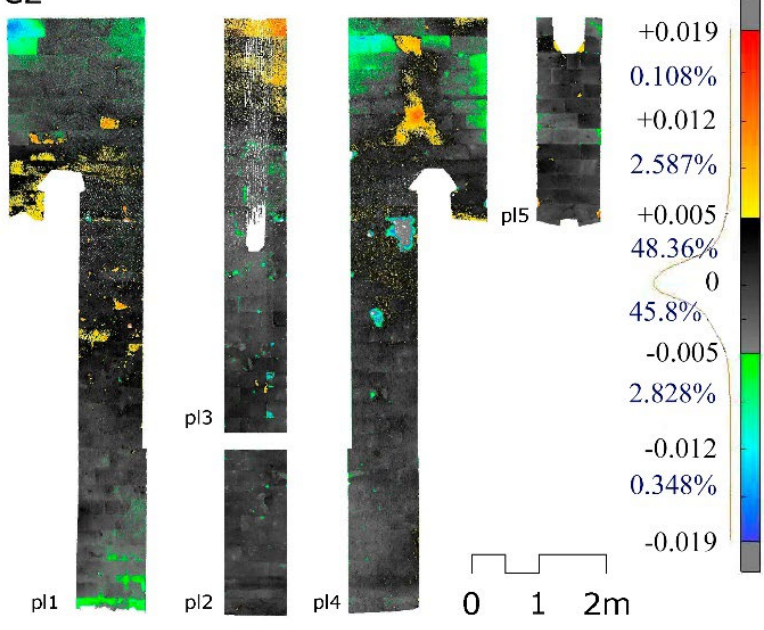

Figure 12: Flatness study of the walls of the lower buttresses.

In general terms, the lower walls $\mathrm{f} 1, \mathrm{f} 2, \mathrm{f} 3, \mathrm{f} 4$ and $\mathrm{f5}$ of the $\mathrm{C} 1$ buttress show a coincidence with their respective best plane of $95.84 \%$ between a range of $\pm 2.5 \mathrm{~mm}$, while in the $\mathrm{C} 2$ buttress the value is $94.16 \%$. In the upper walls, the match of the $\mathrm{f} 6, \mathrm{f} 7$ and f8 walls of the $\mathrm{C} 1$ buttress is $88.10 \%$ in a range of $\pm 2.5 \mathrm{~mm}$, and $89.22 \%$ for the $\mathrm{C} 2$ buttress. 


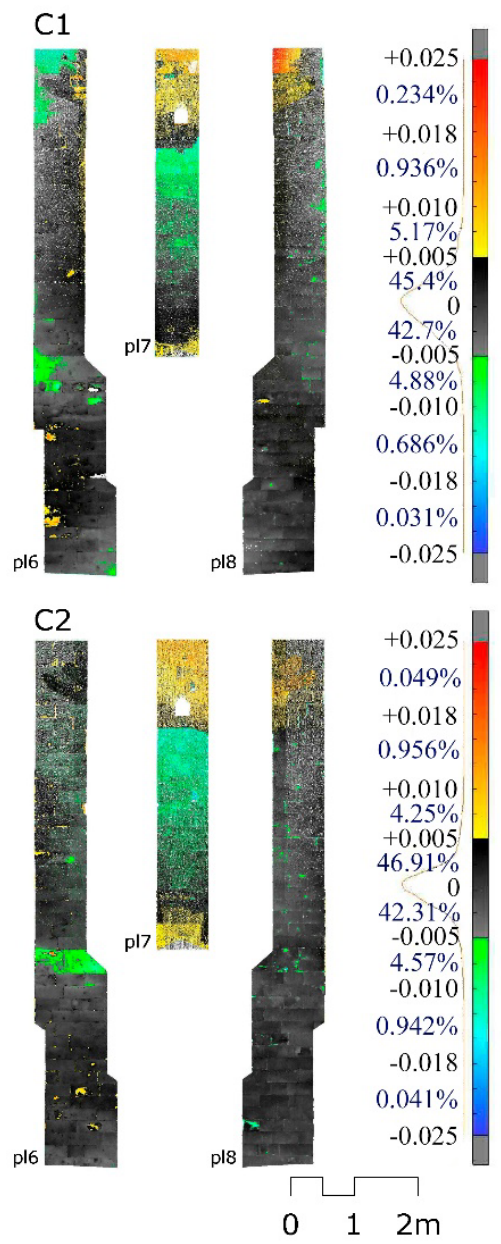

Figure 13: Flatness study of the walls of the upper buttresses.

\section{DISCUSSION}

The results on the arches noted in Table 1 have made it possible to compile a large number of measures that will be very useful in the future when the modular study is applied to the entire apse of the Cathedral of Girona. However, they have already provided some data between arches and similar interesting, such as that in some ribs there is a difference of $5 \mathrm{~cm}$ or that there is no ratio between height and light between the different arches of the vaults. The study by calculating the regression circumferences has allowed to refine the trace of the arches, allowing them to be grouped into four groups depending on their radius, as has been observed in the results. The adjustment of the coefficient of determination in Table 2 shows that the arches and ribs A1.11, A1.1r, A2.21, G1. N3 and G1. N4 have a value of less than $98 \%$, so it could mean that their trace moves geometrically away from a circumference.

As in the arches, the three-dimensional study of the vaults by comparing a horizontal plane does not provide relevant results in a single case, but when comparing all similar vaults with respect to the same plane some differences in heights could be observed. In the study by comparison of cylinders, it is shown that the webs adjust very precisely. The fact that the ends do not finish adjusting with the cylinders shows that the rampant of the vaults is not just linear, but has a certain curvature as can be seen in the bulging towards the interior of the webs pl4 and pl5 of the vault G1 or of the pl1 and pl2 for the case of the central vault B1.
In the pillars, the results show that the out of plumb values are negligible considering their height and section. However, it is curious that in the flatness study the two pillars show a small reduction in their section, with a value of less than $0.019 \mathrm{~m}$. The fact of having compared the pillars with respect to the shape of a theoretical pillar has also allowed to detect some formal difference between pieces that could correspond to their different carving. It should also be noted that the two pillars of the chosen module are linked forming the upper floor where the Chair or "Cadira de Carlemany" is located, so it could have prevented major formal alterations from occurring. This fact could be interesting to compare with the subtraction of pillars of the apse, which are not joined together.

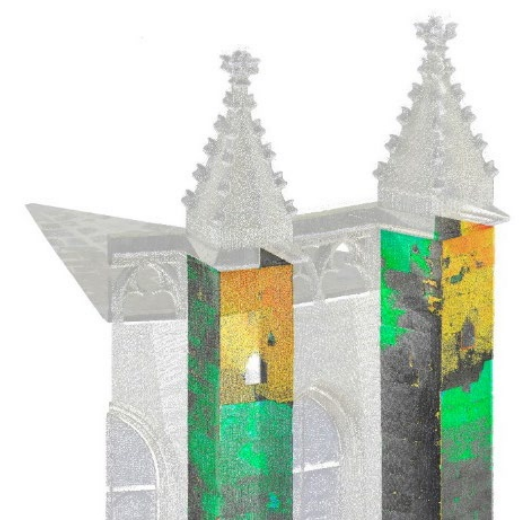

Figure 13: Coincident flatness anomaly in the two upper buttresses.

The leaning values of the buttresses $\mathrm{C} 1$ and $\mathrm{C} 2$, below $4 \mathrm{~mm}$, show that they are not deformed. However, in the flatness study, the front faces of the upper part show an outward displacement of the last third of yarns equally in the two buttresses (Figure 13). Due to its low difference with respect to the subtraction of the wall, it could correspond not to a deformation, but to a constructive phase different from that of the lower part of the buttresses. These yarns are coincident with the level of the roof of the central nave, so constructively the buttresses and pinnacles would have been finished later, generating a constructive joint that could be reflected in this study of flatness of the buttresses.

\section{CONCLUSIONS}

The methodology developed for the analysis of a structural bay in the apse of the Cathedral of Girona has proven to be systematic and clear, providing a large amount of quantitative and qualitative data at both two-dimensional and three-dimensional levels. In some cases, such as in the arches, with their extensive taking of measurements, it may seem to provide few results in this research, without reaching relevant conclusions. However, it is expected that in future research this methodology can be applied to the rest of the modules of the apse, in order to carry out a comparative study that can provide more information about its formal alterations and / or the construction process followed in its construction. In the same way, the study of the vaults could be complemented by the incorporation of some more comparison, such as the analysis between clouds of the different similar vaults, thus discovering if they maintain a formal similarity or there are differences. This fact could help to understand and establish the constructive order followed to cover the ambulatory and the central nave, since there are no historical sources that mention dates of construction of these spaces. There is only evidence of the dates of consecration of the chapels, which 
could correspond approximately to the covering of their vault and which could be validated with this future $2 \mathrm{D}$ and $3 \mathrm{D}$ analysis of their elements. If so, this comparison methodology would be valid to propose an evolution of covering the vaults of the apse.

In this study it has been shown that the different structural elements of the module of the apse of the Cathedral of Girona do not present large formal anomalies that could compromise their structural state. However, the detailed study of flatness in the different walls can yield more constructive information between different phases, contrastable with historical sources and elaborate a constructive evolution of the Cathedral.

Acknowledgments: The survey of the Cathedral of Girona was financed by the Capitol Catedral de Girona through the project T19243S - Aixecament topogràfic de la Catedral de Santa Maria de Girona.

\section{REFERENCES}

Angjeliu, G., Cardani, G., Coronelli, D., 2019. A parametric model for ribbed masonry vaults. Automation in Construction, 105

Barontini, A., Alarcon, C., Sousa, H.S., Oliveira, D.V., Masciotta, M.G., Azenha, M., 2021 Development and Demostration of an HBIM Framework for the preventive Conservation of Cultural Heritage. doi.org/10.1080/15583058.2021.1894502

Boardman, C., Bryan, P., Moitinho, V., 2018. 3D laser scanning for heritage, (February), 113

Bonali, E., Pesci, A., Casula, G., Boschi, E., 2014. Deformation of Ancient Buildings inferred by Terrestrial Laser Scanning methodology: the Cantalovo church case study (Northern Italy). Archaeometry, vol. 56, no. 4, pp. 703-716,

Costa Jover, A., Lluis I Ginovart, J., Coll Pla, S., Piquer, M., Samper-Sosa, A. Moreno Garcia, D., Lorenzo, A., 2017. $3 d$ Surveying And Geometric Assessment Of A Gothic Nave Vaulting From Point Clouds. ISPRS - International Archives of the Photogrammetry, Remote Sensing and Spatial Information Sciences. XLII-2/W3. 203-208. 10.5194/isprs-archives-XLII-2W3-203-2017.

Costa-Jover, A., Moreno Garcia, D., Coll Pla, S., Lluis I Ginovart, J. (2021). From Reality to Point Clouds. Survey and Analysis of Sant Miquel Church of Batea (Spain). SAHC - 12th International Conference on Structural Analysis of Historical Constructions. S24 - Interdisciplinary projects and case studies (1). P. Roca, L. Pelà and C. Molins (Eds.)

Grussenmeyer, P., Landes, T., Voegtle, T., Ringle, K. 2008. Comparison methods of terrestrial laser scanning , photogrammetry and tacheometry data for recording of cultural heritage buildings. International Archives of Photogrammetry, Remote Sensing and Spatial Information Sciences, 37 (B5), pp.213-218.

Kadobayashi, R., Kochi, N., Otani, H., Furukawa, R. 2004. Comparison and evaluation of laser scanning and photogrammetry and their combined use for digital recording of cultural heritage. International Archives of Photogrammetry.

Sinopoli, A., Aita, D., 2021 The Dome of the Temple of Diana in Baiae: Opus aementicium, Geometry and Mechanics.
International Journal of Architectural Heritage, doi.org/10.1080/15583058.2020.1870777

Sureda, M., 2005. Catedral de Girona. Ed. Aldeasa, pp. 52 